\title{
Application of AHP in the "Excellent Lesson Excellent Pay" Course Selection in College
}

\author{
Gang Feng ${ }^{1}$, Chunyan Wang ${ }^{1}$ \\ ${ }^{1}$ School of Economics and Management, Tarim University, Alaer City 843300, China
}

Keywords: Analytic Hierarchy Process, excellent lesson excellent pay, teaching quality evaluation

\begin{abstract}
Teaching quality affects the level of teaching and educational standards in the school. Conducting objective, impartial and scientific evaluation for curriculum teaching quality is an important task of teaching reform. According to the construction of teaching quality evaluation model based on AHP, this paper uses evaluation methods of students teaching evaluation, peer teaching evaluation, supervision teaching evaluation, using AHP to make relevant quantitative indicators of teaching quality and comprehensively evaluate teaching quality so as to objectively and effectively reflect the actual teaching effectiveness, so that it will provide decision-making reference for "excellent lesson excellent pay" course selection. The results show that the Teaching Quality Evaluation System Based on AHP Applies to "excellent lesson excellent pay" course selection, which is an effective evaluation method.
\end{abstract}

\section{Introduction}

Teaching quality is directly related to the quality of personnel training as well as educational quality and standards in the school. In order to improve the overall standard of teaching schools and teaching quality, promote the continuous development of the school teaching, some colleges and universities implement the "excellent lesson excellent pay". That is, according to the relevant management measures, the teachers of teaching curriculum which is rated high quality, will be rewarded to encourage and stimulate the teachers through a variety of methods to enhance the quality of teaching and improve the quality of personnel training, to improve the overall quality of teaching school.

\section{Principle and overview of AHP}

Analytic Hierarchy Process (shortly called AHP) is a multi-objective decision analysis method for quantitative and qualitative combination operations research that T.L.Saaty proposed in the 1970s.

The implementation steps of Analytic Hierarchy Process are as follows:

1. Build the hierarchical structure model, use analytic hierarchy method to classify factors involved in issues, and according to affiliation, dominance relationship to form group, building reasonable and orderly hierarchical structure model from the top to the lowest, tnen constructing evaluation indicator system.

2. Construct judgment matrix, expert advice method is used to quantify the relative importance of each factor of each layer in a "1-9" scale Saaty determined (Table 1) and then build judgment matrix.

Table 1 Scale approach and meaning

\begin{tabular}{l|l} 
Scale & Meaning (Comparison of $\mathrm{A}_{\mathrm{i}}$ and $\mathrm{A}_{\mathrm{j}}$ )
\end{tabular}




\begin{tabular}{|c|c|}
\hline 1 & It represents two factors are equally important \\
\hline 3 & It represents a factor is slightly more important than the other factor \\
\hline 5 & It represents a factor is obviously more important than the other factor \\
\hline 9 & It represents a factor is strongly more important than the other factor \\
\hline $2,4,6,8$ & It represents a factor is extremely more important than the other factor \\
\hline Reciprocal value of the above & \begin{tabular}{c} 
The intermediate value of above adjacent judgment \\
\hline i is $\mathrm{a}_{\mathrm{ji} i=1 / \mathrm{a}_{\mathrm{ij}}}$
\end{tabular} \\
\hline
\end{tabular}

3. Single-level sort, calculating the weight, and making consistency checking. Use the judgment matrix to calculate the relative weight factor, because the judgment matrix cannot have complete consistency, the results will lead to the feature vector deviation of judgment matrix (single-level sort). In order to ensure the rational results obtained by the AHP method, the consistency of judgment matrix need to be examined to decide whether to accept it.

The method of calculating consistency $C I$ is: $C I=\left(\lambda_{\max }-n\right) /(n-1)$; the method of calculating consistency ratio $C R$ is: $C R=C I / R I$. The average random consistency index value $\mathrm{RI}$ is shown by the Table 2look-up.

Only when CR $<0.1$, it is considered that judgment matrix has satisfactory consistency, single-level sort result is credible, or it need to correct the value of judgment matrix until it has satisfactory consistency.

Table 2 the average random consistency index values $(R I)$

\begin{tabular}{|c|c|c|c|c|c|c|c|c|}
\hline Order(n) & 1 & 2 & 3 & 4 & 5 & 6 & 7 & 8 \\
\hline$R I$ & 0.00 & 0.00 & 0.58 & 0.90 & 1.12 & 1.24 & 1.32 & 1.41 \\
\hline
\end{tabular}

4. Total level sorting and consistency check, and conclude. By the weight factor to obtain the total level sorting, after consistency tests have been passed, and each factor weight is ultimately determined. Combine the score of each factor to calculate comprehensive evaluation score of each layer, and thus the overall evaluation based on comprehensive evaluation score is obtained.

\section{Teaching Quality Assessment Model construction of pay “excellent lesson excellent pay”}

The structure of teaching quality assessment system is shown in fig. 1.

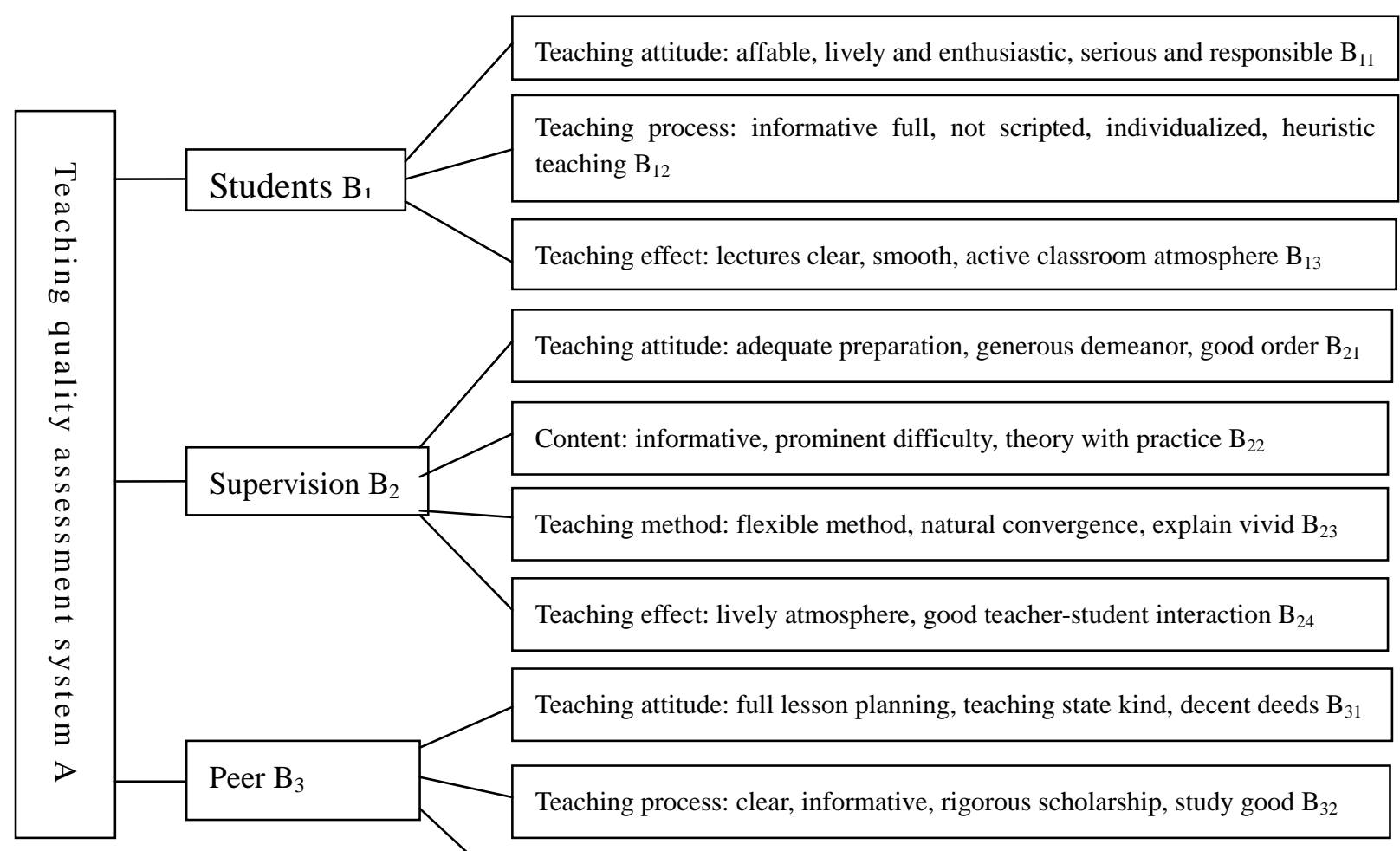


Fig. 1 the structure of teaching quality assessment system

"Excellent lesson excellent pay" teaching quality assessment can be evaluated by students teaching evaluation, peer teaching evaluation, supervision teaching evaluation to comprehensively evaluate teaching quality.

Students teaching evaluation are mainly from three aspects, including teaching attitude, teaching process and results. Evaluation of the teaching attitude mainly examines whether teachers attitude amiable with students, whether lectures vivid enthusiasm, serious and responsible, whether serve as role models. The main teaching process evaluation examines whether the teachers have substantial amount and information is moderate, not scripted in lecture course, whether choose individualized treatment to students, in teaching stage, whether use modern teaching philosophy to make heuristic teaching, so that students' attention is highly concentrated, attracted to classroom teaching. Evaluation of teaching effectiveness mainly depends on whether the teachers organize clear, smooth, prominent focus and difficulty, whether classroom atmosphere is active and so on.

Supervision teaching evaluation is mainly from four aspects, including teaching attitude, teaching content, teaching methods and teaching effectiveness. The teaching attitude mainly examines the adequacy of teacher preparation, whether content is up to date, whether generous demeanor, whether classroom teaching order is good. The teaching content mainly examines whether teacher lectures are substantial, whether the difficulty is prominent and theory is combined with actual situation. Teaching methods mainly sees whether the method of teacher lectures is flexible, whether teaching is natural convergence, whether explain vivid, sound loud, and language smooth. Classroom teaching effect mainly depends on the active atmosphere, whether good teacher-student interaction, whether students' mastering knowledge and acceptance ability is good.

Peer teaching evaluation are from three aspects, including teaching attitude, teaching process and effect. The teaching attitude mainly examine the adequacy of teacher preparation, affable teaching state, decent words and deeds, attention of a teacher. The teaching process mainly relates to clear thinking, substantial content, rigorous scholarship, and good learning atmosphere. The teaching effect are mainly from classroom reflect the good, lively atmosphere, students' ability to absorb, achieve the purpose of teaching.

\section{The index weight determination}

Based on the relationship of each level and each factor in "excellent lesson excellent pay” Teaching Quality Evaluation System to construct the judgment matrix, the add and product method is used to obtain the characteristic value matrix (Wi) and the biggest feature root $\left(\lambda_{\max }\right)$ of judgement matrix of index layer and factor layer, and consistency test is made (Table 3-6).

Table 3 Judgment indicators matrix in criterion layer

\begin{tabular}{|c|c|c|c|c|c|c|c|}
\hline $\mathrm{A}$ & $\mathrm{B}_{1}$ & $\mathrm{~B}_{2}$ & $\mathrm{~B}_{3}$ & $\mathrm{~W}_{\mathrm{i}}$ & $\lambda_{\max }$ & CI & \multirow{2}{*}{$C R$} \\
\hline $\mathrm{B}_{1}$ & 1.0000 & 2.0000 & 3.0000 & 0.5390 & & & \multirow{2}{*}{0.0092} \\
\cline { 1 - 5 } $\mathrm{B}_{2}$ & 0.5000 & 1.0000 & 2.0000 & 0.2973 & \multirow{2}{*}{3.0092} & \multirow{2}{*}{0.0079} \\
\cline { 1 - 5 } $\mathrm{B}_{3}$ & 0.3333 & 0.5000 & 1.0000 & 0.1638 & & & \\
\hline
\end{tabular}

The calculation shows that $C R$ is equal to 0.0079 and less than 0.1 , the results show that the judgment matrix has satisfactory consistency.

Table 4 Judgment matrix of students teaching evaluation index 


\begin{tabular}{|c|c|c|c|c|c|c|c|}
\hline $\mathrm{B}_{1}$ & $\mathrm{~B}_{11}$ & $\mathrm{~B}_{12}$ & $\mathrm{~B}_{13}$ & $\mathrm{~W}_{\mathrm{i}}$ & $\lambda_{\max }$ & $C I$ & $C R$ \\
\hline $\mathrm{B}_{11}$ & 1.0000 & 0.1667 & 0.5000 & 0.1033 & & & \multirow{2}{*}{3.0293} \\
\cline { 1 - 5 } $\mathrm{B}_{12}$ & 5.9988 & 1.0000 & 5.0000 & 0.7225 & \multirow{2}{*}{0.0146} & \multirow{2}{*}{0.0252} \\
\cline { 1 - 5 } $\mathrm{B}_{13}$ & 2.0000 & 0.2000 & 1.0000 & 0.1741 & & & \\
\hline
\end{tabular}

The calculation shows that $C R$ is equal to 0.0252 and less than 0.1 , the results show that the judgment matrix has satisfactory consistency.

Table 5 Judgment matrix of supervision teaching evaluation index

\begin{tabular}{|c|c|c|c|c|c|c|c|c|}
\hline $\mathrm{B}_{2}$ & $\mathrm{~B}_{21}$ & $\mathrm{~B}_{22}$ & $\mathrm{~B}_{23}$ & $\mathrm{~B}_{24}$ & $\mathrm{~W}_{\mathrm{i}}$ & $\lambda_{\max }$ & $C I$ & $C R$ \\
\hline $\mathrm{B}_{21}$ & 1.0000 & 0.2500 & 0.3333 & 0.5000 & 0.0960 & & & \multirow{2}{*}{0.0310} \\
\cline { 1 - 6 } $\mathrm{B}_{22}$ & 4.0000 & 1.0000 & 2.0000 & 3.0000 & 0.4658 & \multirow{2}{*}{4.03103} & 0.0115 \\
\cline { 1 - 6 } $\mathrm{B}_{23}$ & 3.0003 & 0.5000 & 1.0000 & 2.0000 & 0.2771 & & & \\
\hline
\end{tabular}

The calculation shows that $C R$ is equal to 0.0115 and less than 0.1 , the results show that the judgment matrix has satisfactory consistency.

Table 6 Judgment matrix of peer teaching evaluation index

\begin{tabular}{|c|c|c|c|c|c|c|c|}
\hline $\mathrm{B}_{3}$ & $\mathrm{~B}_{31}$ & $\mathrm{~B}_{32}$ & $\mathrm{~B}_{33}$ & $\mathrm{~W}_{\mathrm{i}}$ & $\lambda_{\max }$ & $C I$ & $C R$ \\
\hline $\mathrm{B}_{31}$ & 1.0000 & 0.1429 & 0.5000 & 0.0919 & & & \\
\cline { 1 - 5 } $\mathrm{B}_{32}$ & 6.9979 & 1.0000 & 6.0000 & 0.7545 & \multirow{2}{*}{3.0327} & \multirow{2}{*}{0.0163} & 0.0282 \\
\cline { 1 - 5 } $\mathrm{B}_{33}$ & 2.0000 & 0.1667 & 1.0000 & 0.1535 & & & \\
\hline
\end{tabular}

The calculation shows that $C R$ is equal to 0.0282 and less than 0.1 , the results show that the judgment matrix has satisfactory consistency.

From the secondary and tertiary index weight (single-level sort weight) of Table 3-6, the total level of available sort weights is shown in Table 7.

Table 7 Total level sort of “excellent lesson excellent pay” Teaching Quality Evaluation factor

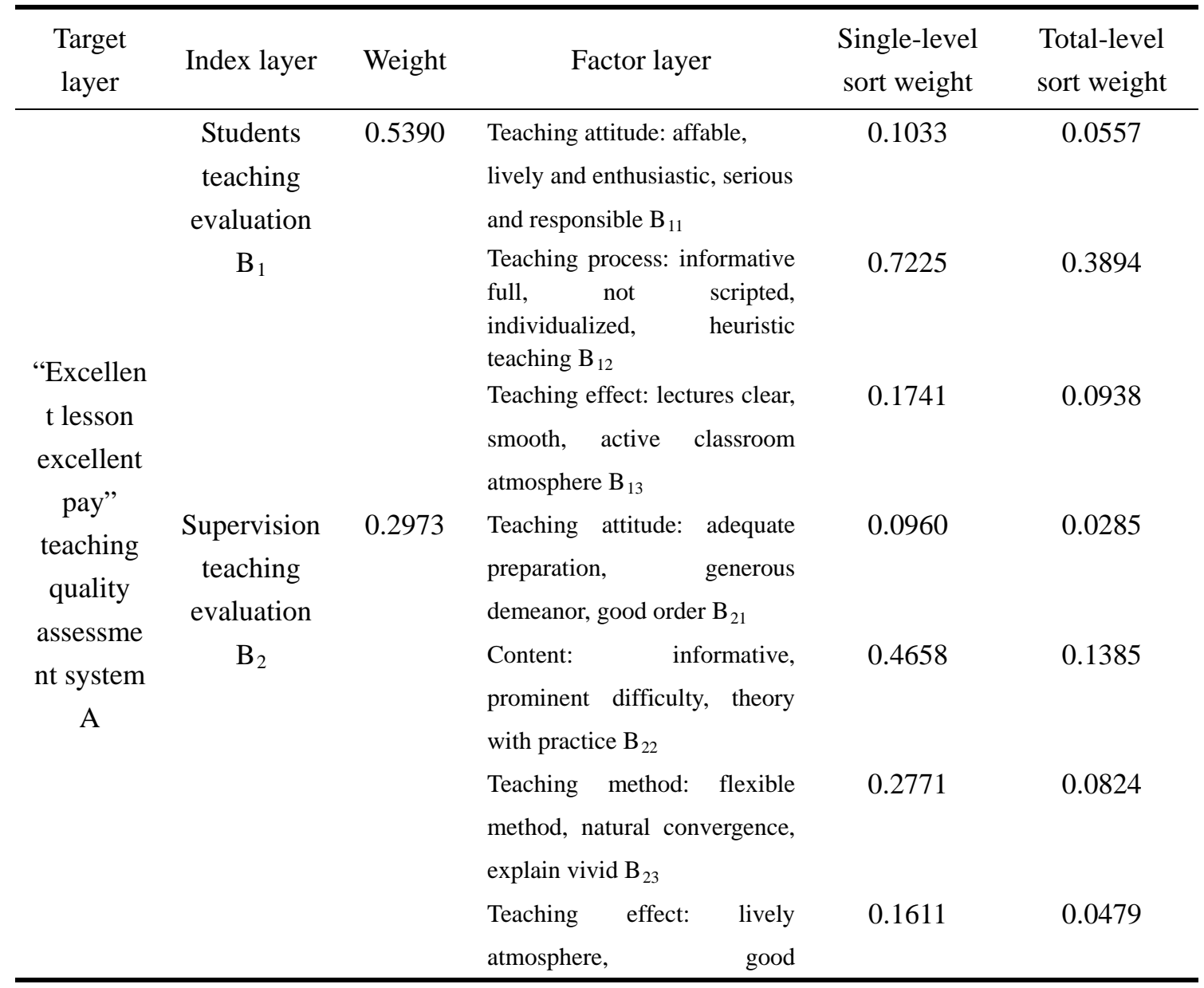




\begin{tabular}{|c|c|c|c|c|}
\hline \multirow{4}{*}{$\begin{array}{c}\text { Peer } \\
\text { teaching } \\
\text { evaluation } \\
\mathrm{B}_{3}\end{array}$} & \multirow{4}{*}{0.1638} & \multicolumn{3}{|l|}{ teacher-student interaction $\mathrm{B}_{24}$} \\
\hline & & $\begin{array}{l}\text { Teaching attitude: full lesson } \\
\text { planning, teaching state kind, } \\
\text { decent deeds } B_{31}\end{array}$ & 0.0919 & 0.0151 \\
\hline & & $\begin{array}{l}\text { Teaching process: clear, } \\
\text { informative, rigorous } \\
\text { scholarship, study good } \mathrm{B}_{32}\end{array}$ & 0.7545 & 0.1236 \\
\hline & & $\begin{array}{l}\text { Teaching effect: classroom } \\
\text { reflect the good, lively } \\
\text { atmosphere, students' ability } \\
\text { to absorb, achieve the purpose } \\
\text { of teaching } B_{33}\end{array}$ & 0.1535 & 0.0251 \\
\hline
\end{tabular}

According to the relevant theoretical and computational data, we need to test the consistency of the overall ranking, for $C I=\sum_{i=1}^{n} a_{i}(C I)_{i}=0.0136, R I=\sum_{i=1}^{n} a_{i}(R I)_{i}=0.6752$, then we get $C R=\frac{C I}{R I}=$ $\frac{0.0136}{0.6752}=0.0201<0.1$. The value of $C R$ is 0.0201 , therefore, the total level sort weights are reasonable, which can be used as a reference for “excellent lesson excellent pay” Teaching Quality Evaluation System.

\section{Application of Teaching Quality Evaluation System in practice}

The “excellent lesson excellent pay” Teaching Quality Evaluation form is shown in Table 8.

Table8 the "excellent lesson excellent pay” Teaching Quality Evaluation form

\begin{tabular}{|c|c|c|c|c|c|}
\hline \multirow[b]{2}{*}{$\begin{array}{l}\text { Evaluation } \\
\text { target }\end{array}$} & \multirow[b]{2}{*}{$\begin{array}{l}\text { Evaluation } \\
\text { index }\end{array}$} & \multirow[b]{2}{*}{ Weight } & \multirow[b]{2}{*}{ Evaluation factor } & \multirow[b]{2}{*}{ Weight } & Evaluation standard \\
\hline & & & & & $\begin{array}{l}\text { Excellent(8.5-10) } \\
\text { Good(7.5-8.4) } \\
\text { Moderate(6.0-7.4) } \\
\text { Poor(5.9 and below) }\end{array}$ \\
\hline \multirow{7}{*}{$\begin{array}{c}\text { “Excellent } \\
\text { lesson } \\
\text { excellent } \\
\text { pay” } \\
\text { teaching } \\
\text { quality } \\
\text { assessment } \\
\text { system }\end{array}$} & \multirow{3}{*}{$\begin{array}{l}\text { Students } \\
\text { teaching } \\
\text { evaluation }\end{array}$} & \multirow{3}{*}{0.5390} & $\begin{array}{l}\text { Teaching attitude: affable, lively } \\
\text { and enthusiastic, serious and } \\
\text { responsible } \mathrm{B}_{11}\end{array}$ & 0.0557 & \\
\hline & & & $\begin{array}{l}\text { Teaching process: informative } \\
\text { full, not scripted, individualized, } \\
\text { heuristic teaching } \mathrm{B}_{12}\end{array}$ & 0.3894 & \\
\hline & & & $\begin{array}{l}\text { Teaching effect: lectures clear, } \\
\text { smooth, active classroom } \\
\text { atmosphere } \mathrm{B}_{13}\end{array}$ & 0.0938 & \\
\hline & \multirow{4}{*}{$\begin{array}{l}\text { Supervision } \\
\text { teaching } \\
\text { evaluation }\end{array}$} & \multirow{4}{*}{0.2973} & $\begin{array}{l}\text { Teaching attitude: adequate } \\
\text { preparation, generous demeanor, } \\
\text { good order } \mathrm{B}_{21}\end{array}$ & 0.0285 & \\
\hline & & & $\begin{array}{l}\text { Content: informative, prominent } \\
\text { difficulty, theory with practice } B_{22}\end{array}$ & 0.1385 & \\
\hline & & & $\begin{array}{l}\text { Teaching method: flexible } \\
\text { method, natural convergence, } \\
\text { explain vivid } \mathrm{B}_{23}\end{array}$ & 0.0824 & \\
\hline & & & $\begin{array}{l}\text { Teaching effect: lively } \\
\text { atmosphere, good teacher-student }\end{array}$ & 0.0479 & \\
\hline
\end{tabular}




\begin{tabular}{|c|c|c|c|}
\hline & & interaction $\mathrm{B}_{24}$ & \\
\hline \multirow{3}{*}{$\begin{array}{c}\text { Peer teaching } \\
\text { evaluation }\end{array}$} & \multirow{3}{*}{0.1638} & $\begin{array}{l}\text { Teaching attitude: full lesson } \\
\text { planning, teaching state kind, } \\
\text { decent deeds } \mathrm{B}_{31}\end{array}$ & 0.0151 \\
\hline & & $\begin{array}{l}\text { Teaching process: clear, } \\
\text { informative, rigorous scholarship, } \\
\text { study good } \mathrm{B}_{32}\end{array}$ & 0.1236 \\
\hline & & $\begin{array}{l}\text { Teaching effect: classroom reflect } \\
\text { the good, lively atmosphere, } \\
\text { students' ability to absorb, } \\
\text { achieve the purpose of teaching } \\
\text { B }_{33}\end{array}$ & 0.0251 \\
\hline
\end{tabular}

The "excellent lesson excellent pay" Teaching Quality Evaluation form in universities is completed by constructing students teaching evaluation, supervision teaching evaluation and peer teaching evaluation, after the index weight calculation and consistency check, the university has formed "excellent lesson excellent pay" Teaching Quality Evaluation form. In order to make the Teaching Quality Evaluation form more operational, it is divided into four levels: excellent (8.5-10), good (7.5-8.4), moderate (6.0-7.4) and poor (5.9 and below), based on the evaluation quantization form, the evaluators give object scores, and thus the quality of teaching evaluation object gets an objective and rational evaluation.

As can be seen from the quality of teaching evaluation form, in the secondary indicator, the weight of students teaching evaluation is the largest, nearly 54 percent; followed by supervision teaching evaluation, nearly 30\%; and peer teaching evaluation has minimum weight, about $16 \%$. In the third indicator, of the students teaching evaluation, the teaching process weight is the largest, followed by the teaching effect, teaching attitude has minimum weight. Of the supervision teaching evaluation, the weight descending sort is teaching content, teaching methods, teaching effect, teaching attitude. Of the peer teaching evaluation, the teaching process weight is the largest, followed by the teaching effect, teaching attitude has minimum weight. The teaching process weight in students teaching evaluation and peer teaching evaluation and the teaching content weight in supervision teaching evaluation account for $65 \%$, which is also consistent with the actual selection situation of "excellent lesson excellent pay” Teaching Quality Evaluation form in universities.

This is a simplified and easy to operate "“excellent lesson excellent pay” Teaching Quality Evaluation system, which is suitable for "excellent lesson excellent pay" course selection, and also in line with the demands of students and teachers. This paper uses AHP to weight evaluation index with the actual teaching evaluation scores, which is more conducive to the accuracy and validity of teaching evaluation results.

\section{Acknowledgement}

This paper is sponsored by Tarim University Higher Education Research: Present Situations and Problems Research of Teacher Evaluation of Students (No: TDGJ1423)

\section{References}

[1] Long Z, Lu J. Operations Research. Wuhan: Wuhan University Press, 2002: 304-308. (In Chinese)

[2] Yang H, Liu J, Cheng X. Application of AHP in Class Teaching Quality Evaluation. Journal of Teaching and Management, 2007. (In Chinese)

[3] Liu C. Simulations for orbital maintenance of low-angle satellite based on STK. Energy Education Science and Technology Part A: Energy Science and Research, 2014, 32(6):6307-6316. 
[4] Saaty T L. Decision making for leaders: the analytic hierarchy process for decisions in a complex world. RWS publications, 1990. 